\title{
Research on the Calibration System of Noncontact Electrostatic Voltmeter by Using the Finite Element Analysis
}

\author{
Jieyu Liu ${ }^{1}$, Wenzuo $\mathrm{Ma}^{2,}{ }^{\text {, }}$, Rundan Zhang ${ }^{1}$, Yidan Zhang ${ }^{1}$ and Jianning $\mathrm{He}^{1}$ \\ ${ }^{1}$ Metering Center, State Grid Liaoning Electric Power Co. Ltd., Shenyang 110000, China \\ ${ }^{2}$ Langfang Power Supply Company, State Grid Jibei Electric Power Co., Langfang 065000, China \\ ${ }^{*}$ Corresponding author
}

\begin{abstract}
Noncontact measurement of electrostatic voltage is required to study the charges in HVDC transmission system. The calibration platform of noncontact electrostatic voltmeter is studied. The electric field near the measurement probe is calculated by FEM. Based on the calculation, the edge effect and applied voltage of the calibrating plate electrode are analyzed.
\end{abstract}

Keywords - calibration; electrostatic voltmeter; finite element method; noncontact measurement

\section{INTRODUCTION}

With the development of HVDC (high voltage direct current) transmission technology, the DC electrical equipment are widely used. Measurement of electrostatic voltage on the objects insulated from the ground is required [1-4]. In GIS (Gas insulated switchgear), the charged particles generated by the high voltage will be induced by the DC electric field, and then accumulated on the insulators [5-8]. The accumulated charges will distort the electric field nearby. The flashover voltage of insulators in GIS will be reduced, and the safe operation of the equipment may be influenced [9, 10]. Under the HVDC transmission lines, the ions generated by the corona discharge will accumulate on the insulated dielectrics or the potential floating conductors. The electric field near the ground may exceed the limitation value, and the electrostatic discharge may happen [11-15].

The electrostatic voltages can be measured by contact or noncontact methods. With respect to the floating potential conductor, the noncontact methods have the advantages of stability. The charges on the floating potential conductor will not be leaked by the internal resistance of measurement device [16-18]. On the surface of dielectrics, the charges cannot move freely. The noncontact method is necessary to measure the electrostatic voltage on the dielectrics [19-23].

The electrostatic voltmeter should be calibrated precisely before being used. The probe of noncontact electrostatic voltmeter should keep an appropriate distance from the calibrating source [24-26]. If the distance is too large, the precision of measured results will be influenced. By contrast, if the distance is too small, the surface charge distribution on the measured test sample will be influenced by the probe.
The edge effect will influence the calibration results, and the influence degree of edge effect depends on the distance between the calibration source and the measurement probe. In the IEC standard and the Chinese standard GJB/J 5972-2007 and JJF 1517-2015, the impact of edge effect is verified by experimental method. In this paper, this problem is studied by electric field calculation. The calculation model is presented by analyzing the measurement principle. The minimum radius and the maximum voltage of high voltage plate electrode is given.

\section{METHODOLOGY}

The calibration platform is illustrated in Figure I. A metal plate electrode is energized by the high voltage DC source, and the radius of the plate is $r$. The measuring probe of electrostatic voltmeter is put at the center of the metal plate. The measuring probe and the metal plate electrode are supported by insulating brackets. The distance between the electrode and the probe is $d$. In this calibration system, the measured signal of electrostatic voltmeter is liner transformed to the voltage on the metal plate electrode.

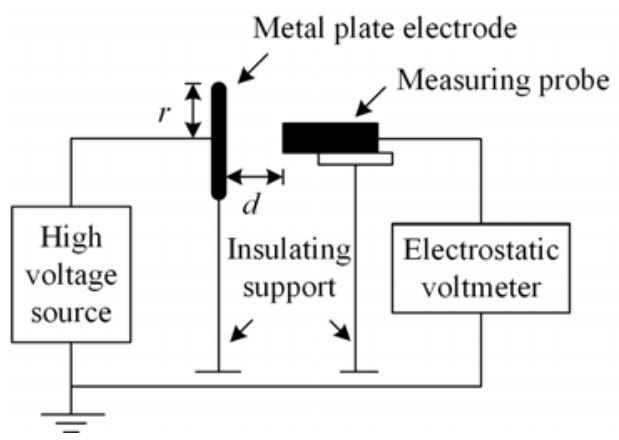

FIGURE I. THE CALIBRATION PLATFORM

The circuit model of the calibration system is shown in Figure II(A). When the probe is static, the distance is marked as $d_{0}$. The capacitance between the metal plate electrode and the vibrant plate in the probe is $C_{0}$, and the capacitance between the metal plate electrode and grounding outer surface of the probe is $C^{\prime}$. The vibrating amplitude is $\Delta d$. 
If the probe and the plate electrode are close enough, the structure can be regarded as a parallel plate capacitance, and $C^{\prime}$ can be neglected. The capacitance of the vibrating system $C$ is

$$
C=\frac{\varepsilon S}{d_{0}+\Delta d \sin w t}=\frac{C_{0}}{1+\eta \sin w t}
$$

Where $\varepsilon$ is the permittivity in the air, $\omega$ and $t$ are the vibrating frequency and time, respectively, $S$ is the area of vibrating plate, and

$$
\eta=\frac{\Delta d}{d_{0}}
$$

The charge $Q$ that stored in $C$ is defined by

$$
Q=C\left(U_{M}-U_{E}\right)
$$

Where $U_{M}$ is the voltage on the metal plate electrode, $U_{E}$ is the voltage on the vibrating plate. In (3), the value of $U_{E}$ is determined by the following equation

$$
\begin{aligned}
U_{E} & =R \frac{\mathrm{d} Q}{\mathrm{~d} t}=R \frac{\mathrm{d} C}{\mathrm{~d} t}\left(U_{M}-U_{E}\right)+R C \frac{\mathrm{d}\left(U_{M}-U_{E}\right)}{\mathrm{d} t} \\
& =R \frac{-\eta \omega C_{0} \cos \omega t}{(1+\eta \sin \omega t)^{2}}\left(U_{M}-U_{E}\right)+R C\left(\frac{\mathrm{d} U_{M}}{\mathrm{~d} t}-\frac{\mathrm{d} U_{E}}{\mathrm{~d} t}\right)
\end{aligned}
$$

Where $R$ is the resistance between the vibrating plate and the ground.

In (4), the value of $U_{M}$ is determined by the voltage source, $\frac{\mathrm{d} U_{M}}{\mathrm{~d} t} \approx 0$. The vibrating plate is very close to the metal plate electrode, $\eta=\frac{\Delta d}{d_{0}}=1$, and $R C \frac{\mathrm{d} U_{E}}{\mathrm{~d} t} \approx R \omega C_{0} U_{E}=U_{E}$. Therefore, (4) can be simplified as

$$
U_{E}=-U_{M} \eta R w C_{0} \cos w t
$$

It can be seen in (5) that $U_{E}$ is proportional to $U_{M}$. When $d$ is increased, the circuit model in (1) need to be modified, and the capacitance $C^{\prime}$ should be considered as well, so (5) cannot be used directly. However, the proportional relationship is still exist. The measured value on the "Output" port is produced by the electric field induction on the vibrating plate. Considering $U_{E} \approx 0$, and $\Delta d \approx 0$, the electromagnetic field model is provided in Figure II(B).

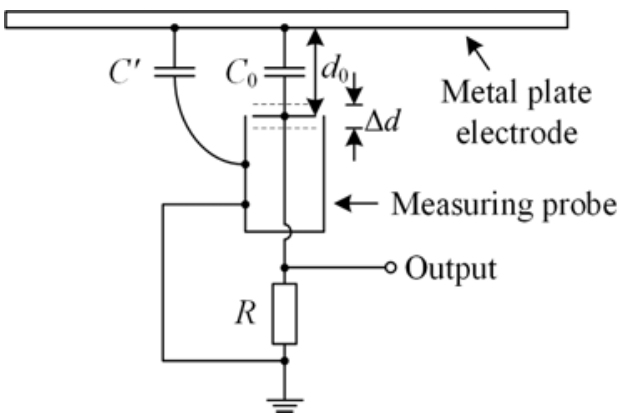

(A)

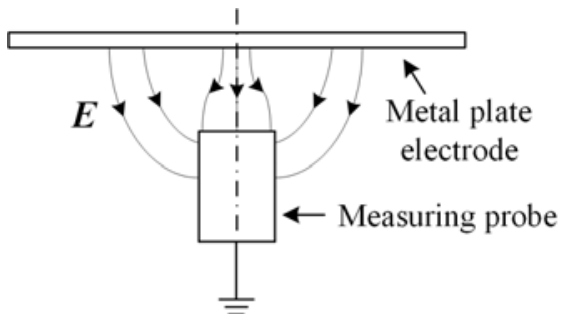

(B)

FIGURE II. THE PROBE OF A NON-CONTACT ELECTROSTATIC VOLTMETER NEAR A CONDUCTIVE PLATE: (A) CIRCUIT MODEL, (B) ELECTROMAGNETIC FIELD MODEL.

The fundamental equation in electrostatic field is the following Laplace equation

$$
\nabla^{2} \varphi=0
$$

Where $\varphi$ is the potential function in the space. The boundary conditions are

$$
\left\{\begin{array}{l}
\left.\varphi\right|_{\Gamma_{M}}=U_{M} \\
\left.\varphi\right|_{\Gamma_{E}}=0 \\
\left.\varphi\right|_{\Gamma_{\infty}}=0
\end{array}\right.
$$

Where $\Gamma_{M}$ is the boundary of metal plate electrode, $\Gamma_{E}$ is the boundary of the probe of electrostatic voltmeter, $\Gamma_{\infty}$ represents the boundary of infinity.

In FEM (Finite Element Method), the equivalent variable problem of Laplace equation (6) is

$$
\begin{aligned}
& J[\varphi]=\iint \frac{\varepsilon}{2}\left[\left(\frac{\partial \phi}{\partial x}\right)^{2}+\left(\frac{\partial \phi}{\partial y}\right)^{2}\right] d x d y \\
& =\frac{1}{2}[\varphi]^{T}[K][\varphi]=\min
\end{aligned}
$$

Where $J[\varphi]$ is the second-order energy functional, $[K]$ is the coefficient matrix of the total electric field energy. According to the extreme value theory of function, there is 


$$
\frac{\partial J}{\partial \varphi}=0
$$

And the discrete form is

$$
[K][\varphi]=[f]
$$

Where $f$ is the energy source in the electric field. In the FEM analysis, the space is meshed by second order triangular element, as shown in Figure III(A).

The charge on the vibrating plate is

$$
Q=\int_{s} \varepsilon E d S=\varepsilon E \cdot S \propto E
$$

Therefore, the variation of output signal can be determined by calculating the electric field on the vibrating plate.

\section{VERIFICATION}

The calculation area in Figure II(B) can be simplified as a 2D symmetrical model. The length of the electrostatic voltmeter probe is $7.5 \mathrm{~cm}$, and the radius is $2.5 \mathrm{~cm}$. In the following calculation, $r=50 \mathrm{~cm}, d=2.5 \mathrm{~cm}$.

The calculation result is shown in Figure III(B). The electric field near the edge of probe is larger than other areas. The electric field distribution shows that the structure cannot be simplified to be a parallel plate capacitor. At the sharp edges of probe, the electric field is significantly distorted. In the practice, these sharp edges can be designed to be smooth edges. Therefore, the center of the probe is chosen to be the reference field point, the electric field on this point is studied.

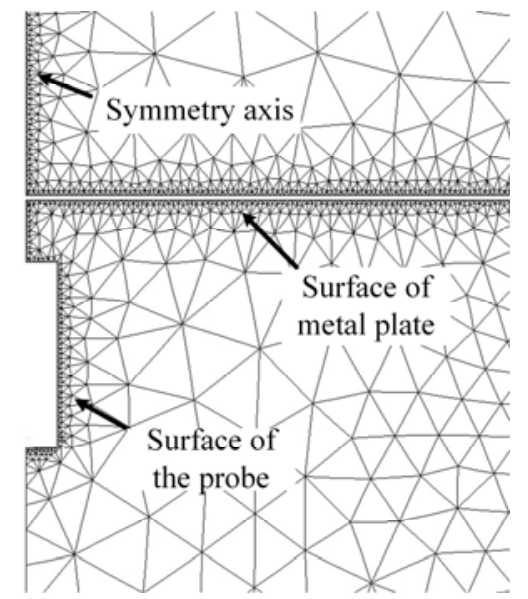

(A)

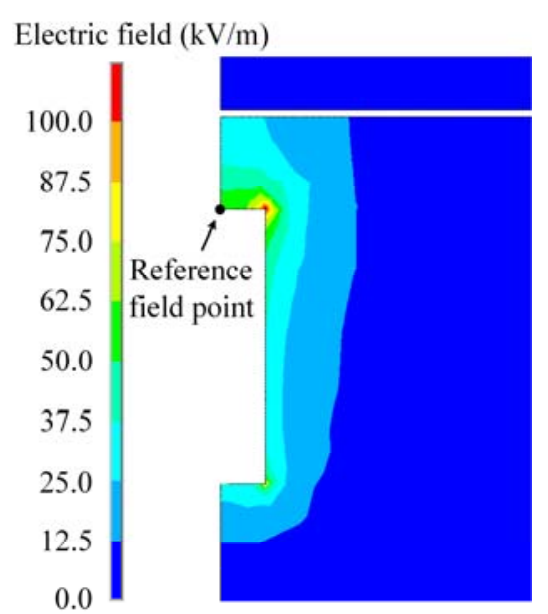

(B)

FIGURE III. FEM ANALYSIS OF THE PROBE, (A) MESHES. (B) CALCULATED ELECTRIC FIELD DISTRIBUTION.

\section{DISCUSSION}

The influence of the radius of metal plate electrode $r$ on the electric field on the reference point is indicated in Figure IV. With the increasing of $r$, the electric field on the probe is increased at first, and then reaches a certain value. When the probe is far away from the metal plate electrode, the electric field strength is decreased.

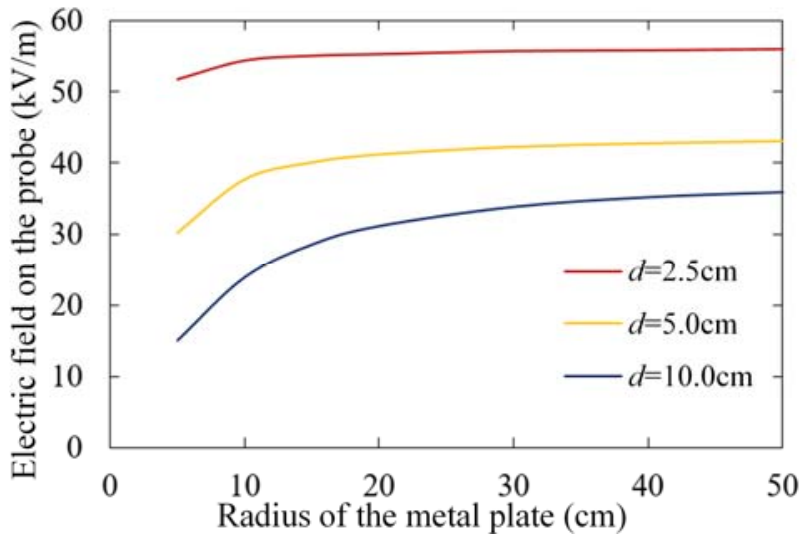

FIGURE IV. INFLUENCE OF BOUNDARY EFFECT ON THE ELECTRIC FIELD

The gradient of the electric fields $E^{\prime}$ in Figure IV is defined as

$$
E^{\prime}=\frac{\mathrm{d} E}{\mathrm{~d} r}
$$

$E^{\prime}$ reflects the edge effect of the metal plate electrode. The calculation results are shown in Figure V. The values of $E^{\prime}$ are reduced to 0 with the increase of $r$. It means the edge effect of metal plate electrode will be weaken by increasing the length of $r$. The farther the distance, the more serious the edge effect. 
The reference value of $E^{\prime}=0.05$ is also marked out in Figure V. When $d=2.5 \mathrm{~cm}, 5 \mathrm{~cm}$ and $10.0 \mathrm{~cm}$, the radius of metal plate electrode should not less than $15 \mathrm{~cm}, 35 \mathrm{~cm}$ and $50 \mathrm{~cm}$, respectively.

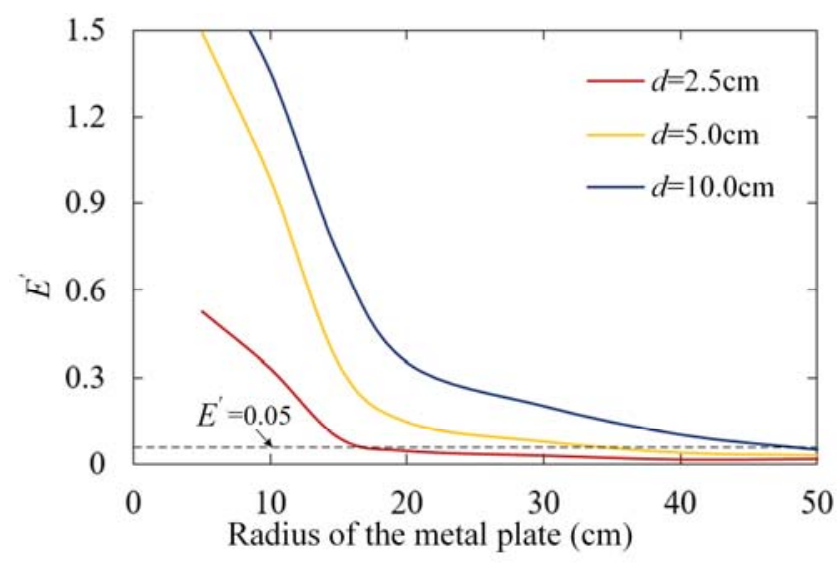

FIGURE V. GRADIENT OF THE RADIUS OF PLATE WITH ELECTRIC FIELD

Except for the edge effect, the voltage on the metal plate electrode also should be limited. If the electric field on the surface of probe exceed the threshold value, corona discharge or spark discharge will happen, and the measurement device might be destroyed. In extremely uneven electric field, $3 \mathrm{kV} / \mathrm{cm}$ is an empirical limitation value of discharge. The electric field at the reference field point is proportional to the voltage on the metal plate electrode, as shown in Figure VI. In order to confine the electric field strength on the reference field point under $3 \mathrm{kV} / \mathrm{cm}$, the voltage on the metal plate should less than $5.5 \mathrm{kV}, 7 \mathrm{kV}$ and $8.5 \mathrm{kV}$ when $d=2.5 \mathrm{~cm}, 5.0 \mathrm{~cm}$ and $10.0 \mathrm{~cm}$, respectively.

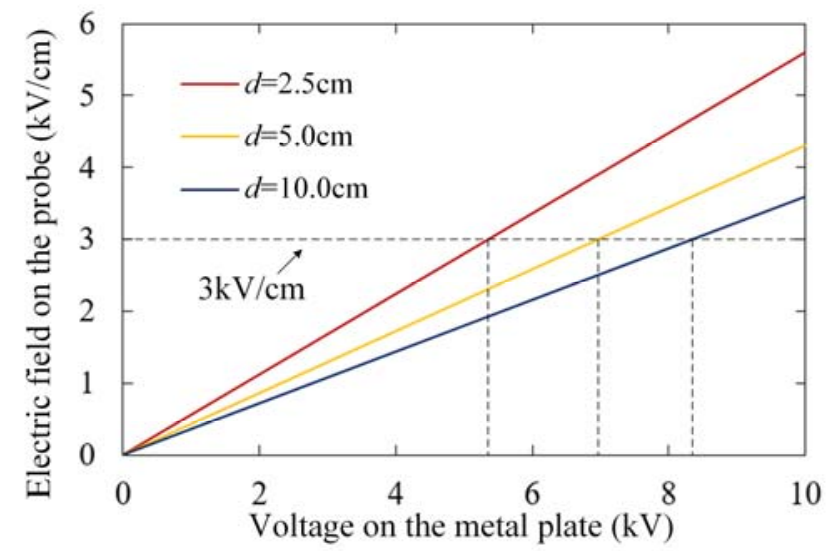

FIGURE VI. INFLUENCE OF VOLTAGE ON THE PROBE SURFACE ELECTRIC FIELD

\section{CONCLUSION}

The calibration system of noncontact electrostatic voltmeter is studied in this paper. Based on the analysis of measurement principles, the electromagnetic field model is presented. Compared with the circuit model, the electromagnetic field model is more suitable for studying the size of metal plate electrode and the applied voltage in the calibration system.

By using FEM analysis, the electric fields near the calibrating electrode and the measurement probe are calculated. When the distances are $2.5 \mathrm{~cm}, 5.0 \mathrm{~cm}$ and $10.0 \mathrm{~cm}$, respectively, the radius of plate should not less than $15 \mathrm{~cm}, 35 \mathrm{~cm}$ and $50 \mathrm{~cm}$, respectively, and the voltage on the metal plate electrode should not exceed $5.5 \mathrm{kV}, 7 \mathrm{kV}$ and $8.5 \mathrm{kV}$, respectively.

\section{REFERENCES}

[1] W. Liu, F. Wang, X. Zhang, "Observation and analysis of insulator surface charge accumulation in GIS," (in Chinese) High Voltage Engineering, vol. 34, no. 8, pp. 1573-1577, 2008.

[2] Y. Murooka, T. Takada, K. Hiddaka, "Nanosecond surface discharge and charge density evaluation Part I: review and experiments", IEEE Electrical Insulation Magazine, vol. 17, no. 2, pp. 6-16, 2001.

[3] T. Kawasaki, T. Terashima, S. Suzuki, "Observation of AC discharge on insulating film by Pockels effect",IEEE Conference on Electrical Insulation and Dielectric Phenomena (CEIDP), 1992.

[4] F. Rossi, G. Opat, A. Cimmino, "Modified Kelvin technique for measuring strain-induced contact potentials," Review of Scientific Instruments, vol. 63, no. 7, pp. 3736-3743, 1992.

[5] A. Kumada, S. Okabe, "Measurement of surface charge on opposite sides of a planar insulator using an electrostatic probe," IEEE Trans. Dielect. \& Elect. Insul., vol. 11, no. 6, pp. 919-928, 2005.

[6] D. Eaircloth, N. Allen, "High resolution measurements of surface charge densities on insulator surfaces," IEEE Trans. Dielect. \& Elect. Insul., vol. 10, no. 2, pp. 285-290, 2003.

[7] H. Ootera, K. Nakanishi, "Analytical method for evaluating surface charge distribution on a dielectric from capacitive probe measurementapplication to a cone-type spacer in + or $-500 \mathrm{kV}$ DC-GIS," IEEE. Trans. Power Deli., vol. 3, no. 1, pp. 165-172, 2002.

[8] Y. Fu, Q. Wang, G. Zhang, X. Wang, "Inverse calculation of surface charge based on surface potential measurement," High Voltage Engineering, vol. 39, no. 1, pp. 88-95, 2013.

[9] Q. Wang, G. Zhang, X. Wang, "Charactieristics and mechanisms of surface charge accumulation on a cone-type insulator under dc voltage," IEEE Trans. Dielect. \& Elect. Insul., vol. 19, no. 1, pp. 150-155, 2012.

[10] Z. Du, G. Huang, J. Ruan, G. Wang, Y. Yao, "Calculation of the Ionized Field Around the DC Voltage Divider," IEEE Trans. Magn., vol. 49, no. 5, pp. 1933-1936, 2013.

[11] Q. Li, B. Chen, D. Wang, T. Lu, X. Bian, "Research on surface charge characteristics of insulating film in ion-flow field" IEEE International Symposium on Electromagnetic Compatibility \& Signal/power Integrity (EMC\&SI), pp. 267-271, 2017.

[12] R. Bai, X. Cui, T. Lu, X. Zhou, J. He, H Hou, "Experimental study on ion-flow fields inside greenhouse models underneath the DC test wire," IEEE Trans. Power Deli., vol. 28, no. 4, pp. 2154-2161, 2013.

[13] W. Ma, T. Lu. "Research on surface charge characteristics of insulating film under HVDC wires with corona discharge," (in Chinese) Power System Technology, vol. 39, no. 6, pp. 1573-1578, 2015.

[14] B. Chen, D. Wang, T. Lu, X. Li, Q. Li, "The influence of water membrane on charge accumulation characteristics of insulating dielectric film," IEEE Conference on Electrical Insulation and Dielectric Phenomenon (CEIDP), Fort Worth, USA, 2017.

[15] W. Ma, T. Lu, D. Wang, L. Wang, X. Qi, S. Sun, "Experimental study on surface charge distribution of insulating film under the HVDC test wire," IEEE International Symposium on Fundamentals of Electrical Engineering, Romania, pp. 1-6, 2015.

[16] F. Wang, Y. Qiu, X. Li, W. Pfeiffer, E. Kuffel, "Insulator surface charge measurement using an improved capacitive probe,". Plasma Sci. \& Technol., vol. 8, no. 5, pp. 565-568, 2006.

[17] R. Kacprzyk, "Measurements of electrical potential of constant charge objects, "IEEE Trans. Dielect. \& Elect. Insul., vol. 19, no. 1, pp. 134$139,2012$. 
[18] M. Lisowski, R. Kacprzyk, "Changes proposed for the IEC 60093 Standard concerning measurements of the volume and surface resistivities of electrical insulating materials," IEEE Trans. Dielect. \& Elect. Insul., vol. 13, no. 1, pp. 139-145, 2006.

[19] D. Taylor, "Measuring techniques for electrostatics," Journal of Electrostatics, vol. 51, no. 1, pp. 502-508, 2001.

[20] N. Othman, M. Piah, Z. Adzis, "Charge distribution measurement of solid insulator materials: A review and new approach," Renewable \& Sustainable Energy Reviews, vol. 70, pp. 413-426, 2017.

[21] A. Fatihou, L. Dascalescu, N. Zouzou, L. Dumitran, "Interpretation of surface potential measurements performed with the vibrating capacitive probe of an electrostatic voltmeter," IEEE Industry Applications Society Meeting, pp. 1-6, 2014.

[22] M. Noras, A. Pandey, "Surface charge density measurements," IEEE Industry Applications Magazine, vol. 16, no. 4, pp. 41-47, 2010.

[23] X. Wang, W. Liu, Q. Wang, H. Zhu, X. Zou, "Measurements of Electric Field and Charge on Insulator Surface," (in Chinese) High Voltage Engineering, vol. 37, no. 3, pp. 732-738, 2011.

[24] R. Kacprzyk, C. Stec, "Measurements of the surface charge density on moving webs," (in Chinese) Journal of Electrostatics, vol. s40-41, pp. 455-461, 1997.

[25] N. Horenstein, "Measuring isolated surface charge with a noncontacting voltmeter," Journal of Electrostatics, vol. 35, no. 2-3, pp. 203-213, 1995.

[26] M. Noras, W. Maryniak, "Non-contacting electrostatic voltmeter for wafer potential monitoring", Proceedings of Spie the International Society for Optical Engineering, vol. 6518, 2007. 